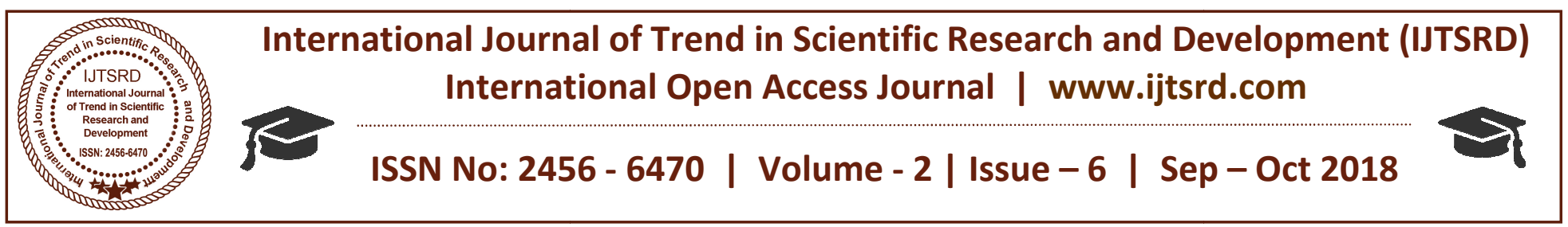

\title{
Efficient Design of 2:1 MUX (Multiplexer) using Nanotechnology Based on QCA
}

\author{
Sohan kumar Dahana, Aastha Hajari \\ Embedded System and VLSI Design, Department of Electronics and Communication Engineering, \\ Shiv Kumar Singh Institute of Technology \& Science (SKSITS), Indore, Madhya Pradesh, India
}

\begin{abstract}
Quantum Dot Cellular Automata is a new technology which overcomes of the of CMOS limitations. It is an novel advanced nano-technology that revolves around the single-electron position control. It is one of the most efficient and emerging nano-technology which mainly deals with the effect of electrons inside the quantum dots in QCA cell, and it is the best alternative technology in the nano-electronics level architectural field. In this paper, we designed a 2:1 Multiplexer, which is more efficient in the term of area and cells to the other designs.
\end{abstract}

Keyword: Wire, Inverter, Majority Voter, CMOS, VLSI, Quantum dot cellular automata, Multiplexer, Quantum cell.

\section{INTRODUCTION}

QCA is a promising technology that provides a very efficient computational platform than CMOS is a nano-technology approach i.e. Quantum cellular automata (QCA) [1, 2]. It represents the digital information by polarization of electrons. It is attractive for its size, faster speed, feature, highly scalable, higher switching frequency and low power consumption compared to CMOS technology $[4,5,6]$. The four quantum dots form a QCA cell with one electron each in two of the four dots occupying "diametrically opposite" locations. Electrons occupy opposite (diagonal) corner quantum-dots because Coulomb repulsion is less compared to the scenario when they are in adjacent quantum dots [7,8].

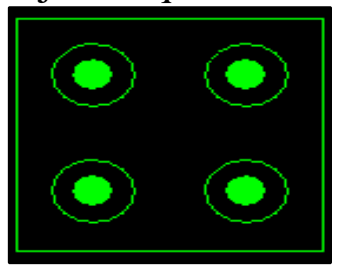

Fig. 1: Empty cell

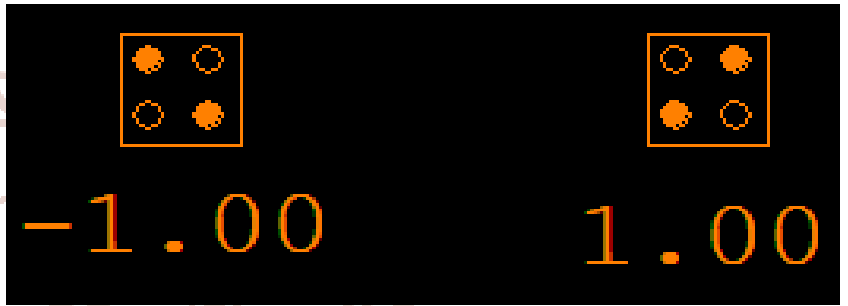

(a): $P=-1($ Binary 0), $\quad$ (b) $P=1($ Binary 1$)$

Fig.2: Quantum-dots $90^{\circ}$ cells polarizations

The new computing paradigm, QCA has been extensively studied in recent years. The basic element in Quantum dot cellular automata is a "cell" that consists of four metal islands dots known as QD [9, $10]$. It's positioned at the corners of squared cell and two free charges [10].

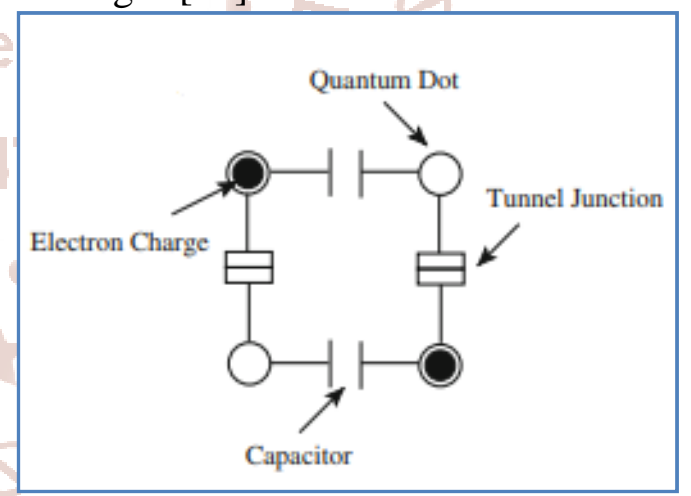

Fig. 3: Basic QCA Cell [10]

\section{MULTIPLEXER}

A Multiplexers (MUX) is a combinational logic component that has several inputs and only one output. MUX directs one of the inputs to its output line by using a control bit word (selection line) to its select lines. A multiplexer can take any number of inputs line but then the selection line will be according to the number of inputs. The relation between the selection lines and the input lines is given in the equation 1 . 
International Journal of Trend in Scientific Research and Development (IJTSRD) ISSN: 2456-6470

$$
2^{M}=N
$$

Where $\mathrm{M}$ is the selection lines and $\mathrm{N}$ is the number of input lines.

\section{QCA DESIGN}

Research on binary majority decision elements motivated by the development of devices such as parametrons and Esaki diodes has been reported as early as 1960 . The majority function or majority voter consist of only three input QCA cells implements the logic function is Eq. 2. Where A, B, and $\mathrm{C}$ are inputs and $\mathrm{F}$ is the single output as shown in fig. 8. The basic element of QCA is wire is shown in figure 4, inverter in figure 6.

$$
\mathrm{F}=\mathrm{AB}+\mathrm{BC}+\mathrm{AC}
$$

\section{A. QCA Wire Design}

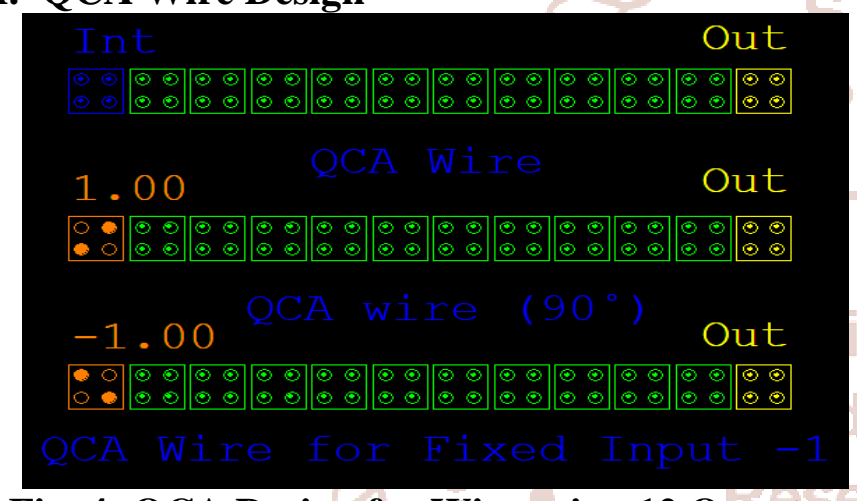

Fig. 4: QCA Design for Wire using 12 Quantum Cells as consider $90^{\circ}$ (Normal cell) cell

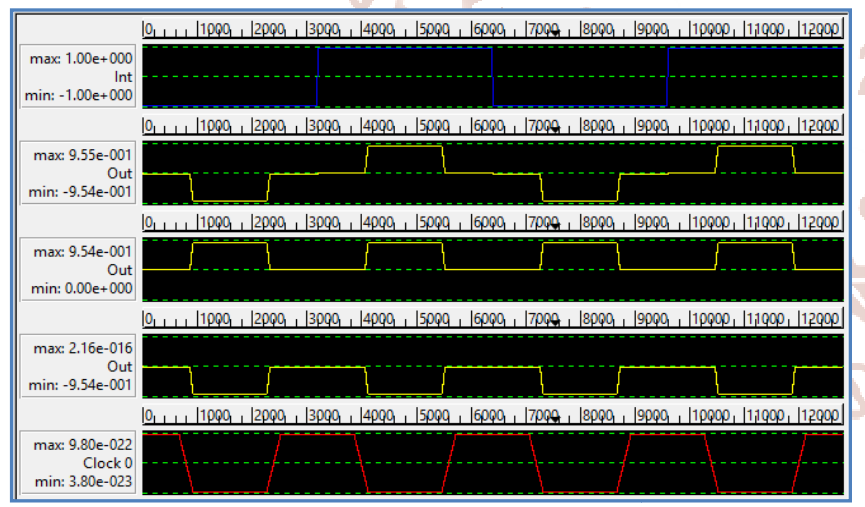

Fig. 5: Simulation result for QCA wire as consider Normal cell for $90^{\circ}$

\section{B. QCA INVERTER DESIGN}

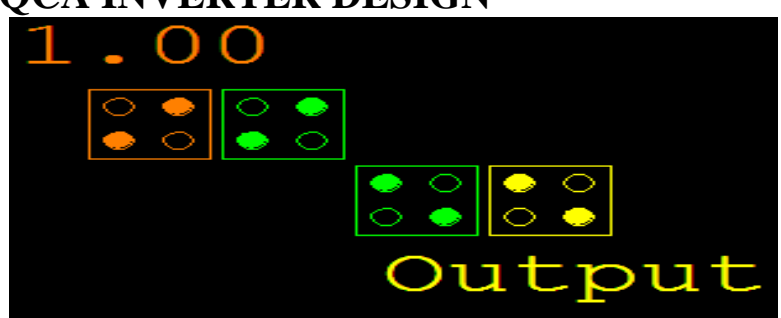

Fig. 6: Layout of an "alternate inverter" configuration

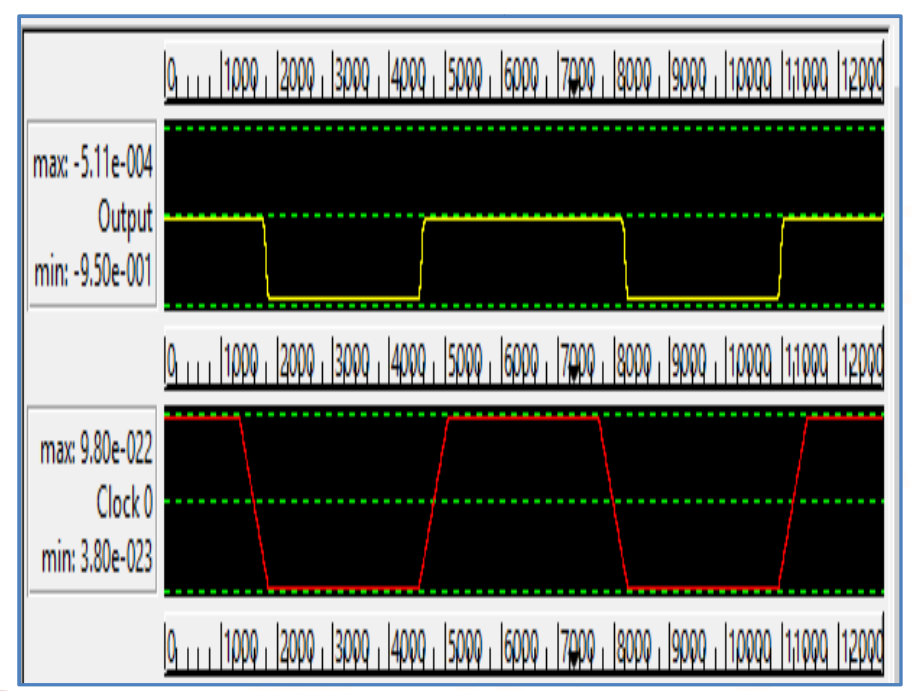

Fig. 7: Simulation result for an "alternate inverter" configuration

\section{QCA 3-Input Majority Logic}

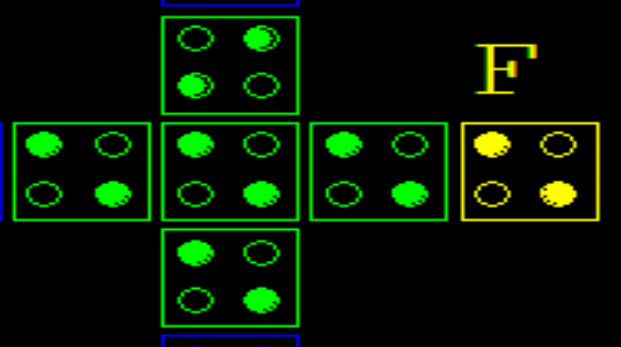

Fig. 8: Layout of majority voter (MV) consist of three input QCA cells

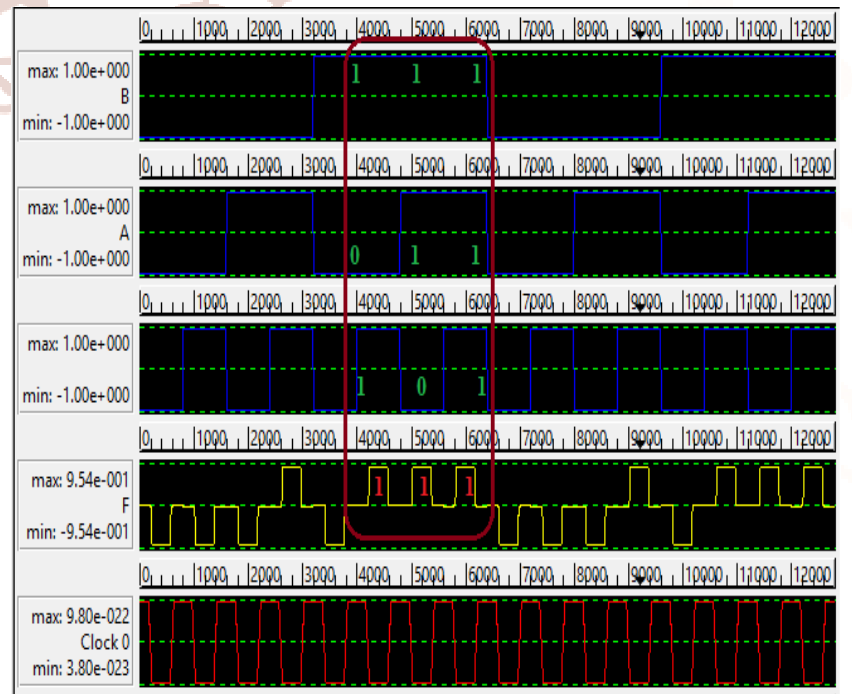

Fig. 9: Simulation result for majority voter (MV) consist of three input QCA cells 
International Journal of Trend in Scientific Research and Development (IJTSRD) ISSN: 2456-6470

\section{Bi-STABLE PARAMETERS}

To verify our proposed layout designs of different logic gates on used recent specific resolution tool QCA Designer version 2.0.3 with the bistable simulation engine setup.

Table 1: Bistable Simulation Parameters

\begin{tabular}{|c|c|c|}
\hline Parameter & Value & \\
\hline Cell width & $18 \mathrm{~nm}$ & \multirow{4}{*}{$\begin{array}{c}\text { Layer } \\
\text { Properties }\end{array}$} \\
\hline Cell height & $18 \mathrm{~nm}$ & \\
\hline $\begin{array}{l}\text { QCA-Quantum-dot } \\
\text { diameter }\end{array}$ & $5 \mathrm{~nm}$ & \\
\hline Default Clock & Clock 0 & \\
\hline Time-step & $1.0 \mathrm{e}-16 \mathrm{~s}$ & \multirow{7}{*}{$\begin{array}{c}\text { Bistable } \\
\text { Approximation } \\
\text { (Options) }\end{array}$} \\
\hline Relaxation time & $1.0 \mathrm{e}-15$ & \\
\hline Clock-low & $\begin{array}{l}3.8 \mathrm{e}- \\
023 \mathrm{~J} \\
\end{array}$ & \\
\hline Clock-high & $\begin{array}{l}9.8 \mathrm{e}- \\
022 \mathrm{~J} \\
\end{array}$ & \\
\hline Radius of effect & $65 \mathrm{~nm}$ & \\
\hline Relative permittivity & 12.90 & \\
\hline Layer separation & $1.50 \mathrm{~nm}$ & \\
\hline
\end{tabular}

\section{PROPOSED DESIGN}

The truth table of the 2-to-1 multiplexer is shown in table 2. depending on the selector $(\mathrm{S})$ switching the inputs are produced at outputs, i.e., $\mathrm{D}_{0}, \mathrm{D}_{1}$ and are switched to the output for $S=0$ and $S=1$ respectively . Thus, the Boolean expression for the output becomes $\mathrm{D}_{0}$ when $\mathrm{S}=0$ and output is $\mathrm{D}_{1}$ when $\mathrm{S}=1$. From the truth table the Boolean expression of the output $\mathrm{Y}$ is given as:

$$
Y=D_{0} \bar{S}+D_{1} S
$$

Table 2: Truth table for 2:1 MUX

\begin{tabular}{|c|c|c|c|}
\hline Select & \multicolumn{2}{|c|}{ Inputs } & Output \\
\hline S & A & B & Y \\
\hline 0 & 0 & 0 & 0 \\
\hline 0 & 0 & 1 & 1 \\
\hline 1 & 1 & 0 & 1 \\
\hline 1 & 1 & 1 & 1 \\
\hline
\end{tabular}

This is because of its ability to select one signal out of many inputs. We are proposed 2:1 MUX design in figure 10 based on quantum cells shown in figure 10 first proposed design, quantum cells 24 , used design area in $0.04 \mu \mathrm{m}^{2}$.

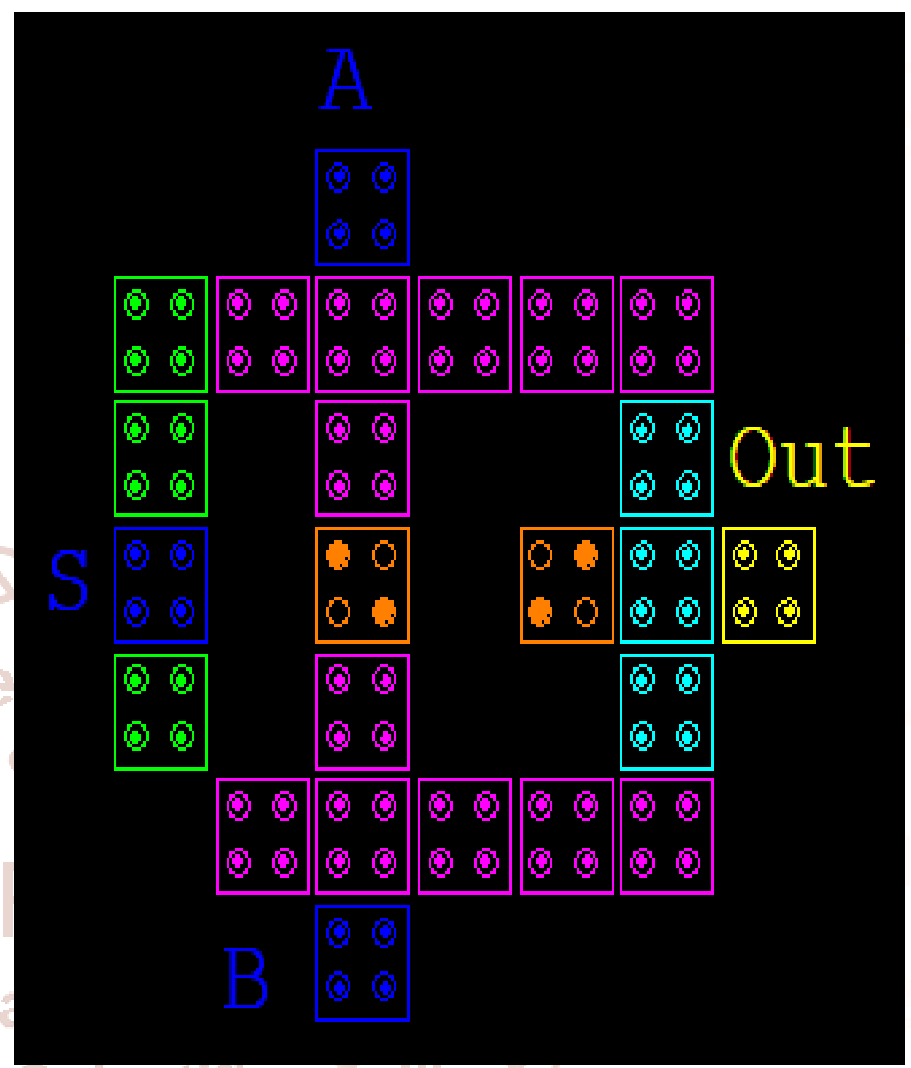

Fig. 10: First proposed 2:1 multiplexer design using 24 Quantum cells

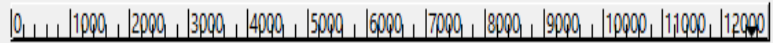

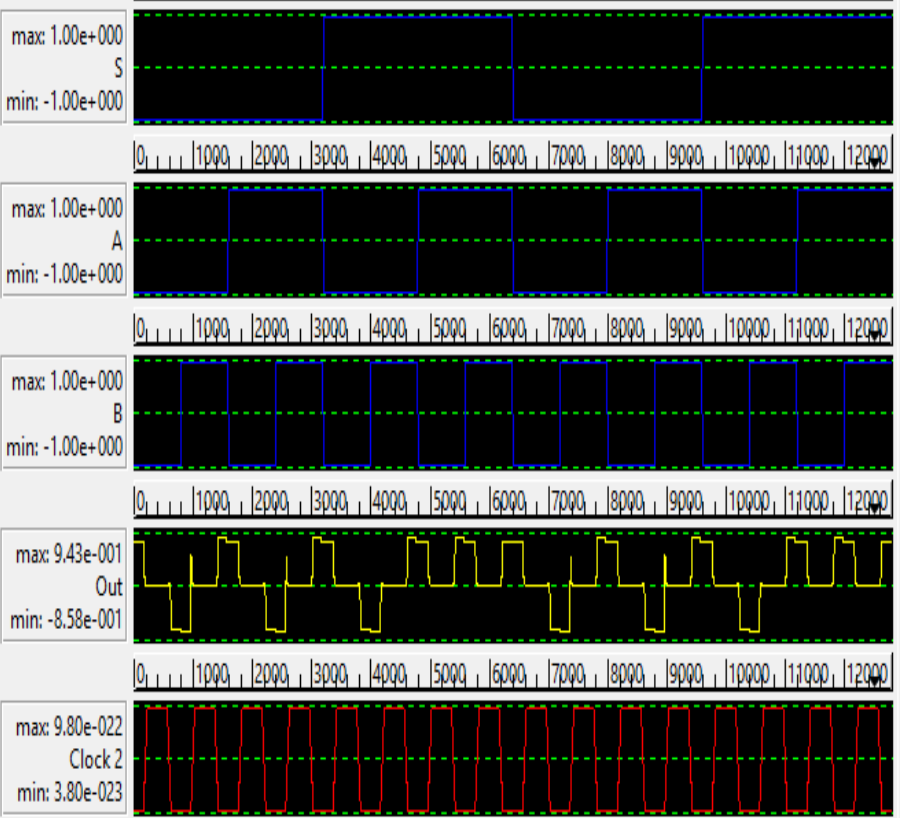

Fig. 11: Simulation Output for 2:1 multiplexer design using 24 Quantum cells

Result Analysis: Selection extents: (156.19, 150.31) [228.04x 162.88] $=37142.55 \mathrm{~nm}^{2}=0.04 \mu \mathrm{m}^{2}$ Objects selected: 24 . 
Table 3: The comparative table for the 2:1 QCA multiplexer architectures

\begin{tabular}{|c|c|c|c|c|}
\hline Authors Name & Number of Cells & Area & Clock Delay & Wire Crossing \\
\hline V.A. Mardiris et al. [4] & $\mathbf{5 6}$ & 0.07 & 4 & Coplanar \\
\hline A. Roohi et al. [5] & $\mathbf{2 7}$ & 0.03 & 3 & Coplanar \\
\hline R. S. Nadooshan et al. [7] & $\mathbf{2 6}$ & 0.02 & 3 & Coplanar \\
\hline Proposed Design-1 [Fig. 10] & $\mathbf{2 4}$ & 0.03 & 2 & Coplanar \\
\hline
\end{tabular}

\section{CONCLUSION}

The MUX are important part of digital logical circuits and control systems. In this paper, proposed designs for QCA 2:1 MUX were reviewed. The functionality of the proposed circuits is necessary to validate the designs using the QCA Designer bistable engine [10]. The proposed design, in term of cells, has better operation compared to the other existing some designs.

\section{REFERENCES}

1. Jadav Chandra Dasa \& Debashis De, Indian Journal of Pure \& Applied Physics Vol. 54, December 2016, pp. 802-811.

2. Mrinal Goswami, Brajendra Kumar, Harsh Tibrewal, Subhra Mazumdar, 2014-2nd International Conference on Business and Information Management (ICBIM), 978-1-47993264-1114/\$31.00 @2014 IEEE.

3. Hamid Rashidi, Abdalhossein Rezai, Journal Of Nano- And Electronic Physics, Vol. 9 No 1, 01012(7pp) (2017).

4. V.A. Mardiris, I. G. Karafyllidis, Int. J. Circ. Theor. Appl. 38(8), 771 (2010).
5. A. Roohi, H. Khademolhosseini, S. Sayedsalehi, K. Navi, Int. J. Comput. Sci. Issues 8(6), 55 (2011).

6. B. Sen, M. Dutta, D. Saran, B. Sikdar, Lecture Notes Comput. Sci. 7373, 350 (2012).

7. R. Sabbaghi-Nadooshan, M. Kianpour, J. Comput. Electr. 13(1), 198 (2013)

8. B. Sen, A. Nag, A. De, B.K. Sikdar, J. Comput. Sci. 11, 233 (2015)

9. Purkayastha, T., Debashis, D., Chattopadhyay, T., (2016), Ain Shams University, Production and hosting by Elsevier, Ain Shams Engineering Journal.

10. Patidar M., Gupta N. (2019), In: Nath V., Mandal J. (eds) Proceeding of the Second International Conference on Microelectronics, Computing \& Communication Systems (MCCS 2017). Lecture Notes in Electrical Engineering, vol 476. Springer, Singapor

11. Patidar, N., Gupta, N., Amita K., Sumant, Katiyal, S., Choudhary, K.K.,(2013), international journal of nanotechnology and Application (IJNA), 3(2), pp. 1-8.

12. Kumar, D., Mitra, D., (2016), Elsevier, Microelectronics Journal 53, pp 90-104. 